\title{
QUALITY OF LIFE OUTCOMES IN PATIENTS WITH COLOSTOMY AND ILEOSTOMY, WITH REFERENCE TO PSYCHOSOCIAL PROBLEMS AND SURGICAL COMPLICATIONS
}

\author{
Subhasish Sarkar ${ }^{1}$
}

${ }_{1}^{1}$ RMO-cum-Clinical Tutor, Department of General Surgery, College of Medicine and Sagore Dutta Hospital, Kolkata, West Bengal, India. ABSTRACT

\section{BACKGROUND}

Stoma surgery is a lifesaving procedure performed for the management of several benign and malignant gastrointestinal problems. Restricted physical and social activities with disturbed sexual relationships are common causes of a poor quality of life (QOL) in this group of patients. This study aims to accurately assess the QOL of patients undergoing stoma surgery using a QOL assessment tool.

\section{MATERIALS AND METHODS}

This was cross sectional observational study. 60 patients were interviewed about their quality-of-life dimensions by purposeful sampling. predesigned proforma. "Quality of Life Enjoyment and Satisfaction Questionnaire" was used during scheduled interview with patients.

\section{RESULTS}

Skin irritation was seen in $85.3 \%$ of patients with benign disease against $61.5 \%$ of patients with malignant cause as primary disease, $p$ value 0.035 . Patients undergoing intestinal stoma surgery, who had undergone preoperative counselling, have significantly low skin irritation problems with p value 0.005 . For psychological wellbeing, the median raw score for all patients was 65 , range 46 to 80 , with score of $6.45 \pm 0.08$. The psychological score was higher in non-counseling arm $6.61 \pm 0.55$ versus $5.68 \pm$ 0.69 in counseled arm, p value $<0.001$.

\section{CONCLUSION}

Detailed preoperative counseling explaining the course of treatment is the key for an excellent recovery. Identification of data in the perspective of scant presence of Indian data will allow caregivers to formulate strategies for better stoma management with formation of the stoma care team.

\section{KEY WORDS}

Ileostomy, Colostomy, QOL, Surgical Complications, Psychosocial Complications.

HOW TO CITE THIS ARTICLE: Sarkar S. Quality of life outcomes in patients with colostomy and ileostomy, with reference to psychosocial problems and surgical complications. J. Evolution Med. Dent. Sci. 2018;7(49):5292-5297, DOI: $10.14260 /$ jemds/2018/1173

\section{BACKGROUND}

Surgical procedures involving ileostomy or colostomy are usually performed in many conditions, some of which are congenital, and others are acquired. Congenital disorders include anorectal malformations, Hirschsprung disease etc. Acquired conditions are bowel neoplasia, inflammatory bowel diseases, abdominal trauma, intestinal perforation, severe idiopathic constipation, and intestinal obstruction with gangrenous changes. Intestinal stoma can be either permanent or temporary. Constructing stoma affects the patient's quality of life (QOL) to a variable extent. Patients usually suffer from skin excoriation, sleep disturbance and many social problems. Restricted physical and social activities with disturbed sexual relationships are common causes of a poor QOL in this group of patients.

'Financial or Other Competing Interest': None.

Submission 20-10-2018, Peer Review 20-11-2018,

Acceptance 26-11-2018, Published 03-12-2018.

Corresponding Author:

Dr. Subhasish Sarkar,

RMO-Cum-Clinical Tutor,

Department of General Surgery,

College of Medicine and Sagore Dutta Hospital,

Kolkata, West Bengal, India.

E-mail: s.sarkar735@gmail.com

DOI: $10.14260 /$ jemds $/ 2018 / 1173$
Accurate assessment of QOL in stoma patients will provide better understanding which will lead to subsequent improvement of QOL in these patients.[1] Although the number of stoma surgery is growing day by day, it is unfortunate that this particular aspect of impact of stoma on QOL has not yet been addressed in any Indian study. Therefore, this study aims to accurately assess the QOL of patients undergoing stoma surgery using a QOL assessment tool.

\section{Review of Literature}

Stoma surgery is a life saving procedure performed for the management of several benign and malignant gastrointestinal problems. The incidence of permanent stoma surgery has reduced in recent years due to technical advancement in restorative rectal surgery and sphincter salvage. The quality of life of most stoma patients is affected to variable extent due to physical and psychosocial limitations as a result of the stoma. Advanced surgical technique and skilful stoma nursing along with precise assessment of subjective QOL are essential for a satisfactory outcome. Detailed preoperative counselling explaining the course of treatment is the key for an excellent recovery.

\section{The Main Types of Intestinal Stoma are-}

1. Ileostomy: end, loop, double barrel (Figure 1)

2. Colostomy: end (Figure 2) and loop. 


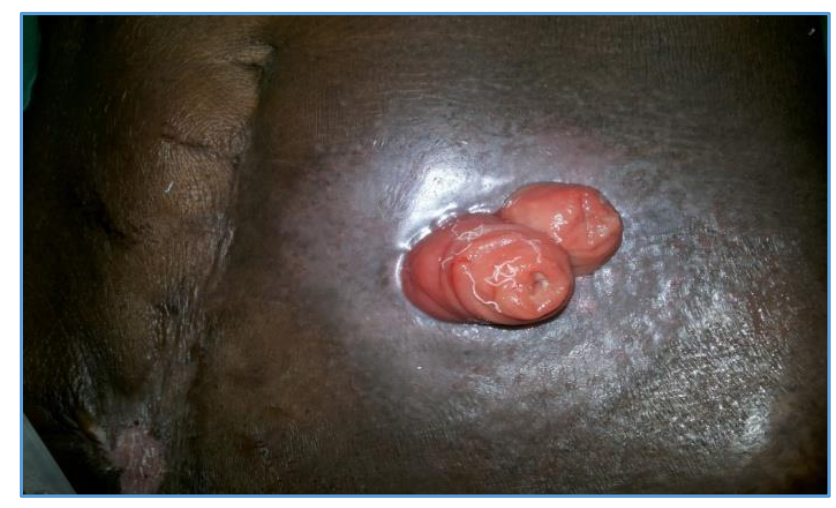

Figure 1. Double Barrel Ileostomy

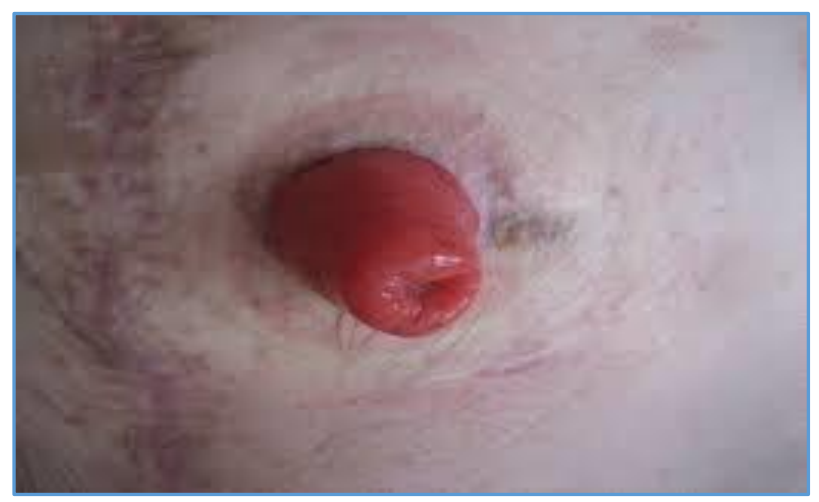

Figure 2. End Colostomy

\section{Surgical Complications of Stoma}

There are several surgical complications of intestinal stoma of them skin irritation is most common. Other complications include mucocutaneous separation, bleeding, parastomal hernia, stoma prolapse, parastomal ulcer and ischemia.

\section{Justification of the Proposed Research Work}

The formation of an intestinal stoma is one of the most frequent operations in visceral surgery and results in a significant change in the patients' quality of life. Assessment and identification of the problems faced by the patient in adjusting to his/her stoma is directed at decreasing the high morbidity (physical, social and psychological) associated with formation of a stoma, temporary or permanent.

\section{Research Hypothesis}

The hypothesis is based on the notion that stoma formation for both benign and malignant disease adversely affects the quality of life. The degree of affection is being evaluated by the "Quality of Life" score enumerating physical, psychological, economical \& social aspects. The impact of the surgical procedures on the QOL as related to stoma complications, temporary versus permanent stoma formation and the impact of pre-operative counselling on decreasing morbidity was quantified.

\section{Aims and Objectives}

1. To study the prevalence and impact of stoma related surgical complications.

2. To assess the subjective quality of life with intestinal stoma.

\section{MATERIALS AND METHODS}

Study Area

R. G. Kar Medical College \& Hospital; Department of General Surgery. It is a tertiary care teaching hospital catering a cosmopolitan population of a metropolitan city and the surrounding districts and also the adjoining states and country.

\section{Study Population}

All patients undergoing abdominal surgery with colostomy or ileostomy formation in elective or emergency procedures.

\section{Inclusion Criteria}

a. Adult Patients with temporary ileostomy and colostomy.

b. Adult patients with permanent ileostomy and colostomy.

\section{Exclusion Criteria}

a. Patients with age less than 18 years as psychometric data assessment may be inadequate.

b. Adult patients with inadequate mental judgment and ability to respond to the verbal questionnaire.

c. Presence of other major co morbid diseases causing significant morbidity and confounding the QOL.

d. Patients not desirous of participating in the study.

\section{Study Period}

January 2013 to June 2014.

\section{Sample Size}

Projected sample size was 68 patients. And actual size is 60 patients.

\section{Sample Design}

The study population selected from: All patients undergoing abdominal surgery with stoma formation (colostomy/ ileostomy) in elective or emergency procedures during hospital stay and during follow up in Surgical OPD or Oncology OPD (for cancer patients). The assessment made at the time of first OPD visit since the Stoma formation.

\section{Study Design}

It was an observational study. Selected questionnaire was asked regarding quality of life to each patient who underwent stoma surgery.

\section{Parameters Studied}

a. Stoma related surgical complications.

b. Physical problems.

c. Psychological problems.

d. Social problems.

No points for counselling were given. Stoma surgery is partly elective and emergency. As it is a cross sectional study we asked if the patients got counselled before surgery or not.

\section{Study Tools}

Predesigned Performa, "Quality of Life Enjoyment and Satisfaction Questionnaire" after Scheduled interview with patients. The Stoma Quality of life scoring system, a predesigned Performa validated for use was designed by the stoma research board. City of Hope National Medical Center, Durate and Beckman Research Institute. 


\section{Study Techniques}

The study performed was cross sectional observational study. Sixty patients were interviewed about their quality of life dimensions by purposeful sampling. Data was gathered by interviews and analysed using the content analysis method.

\section{Analysis of Data}

Sample size was based on a crossover pilot study of 8 patients and was selected to detect a projected difference of $10 \%$ in psychological wellbeing score (i.e. 6.5) for producing psychological wellbeing among two groups for a type 1 error of 0.05 and a power of 0.8 . On the basis of various previous studies, assuming within group SD of 0.66 hour and we needed to study at least 60 patients per group to be able to reject the null hypothesis which will be increased to 68 patients for possible dropouts.

Raw data were entered into a MS Excel spreadsheet and analyzed using standard statistical software SPSS ${ }^{\circledR}$ statistical package version 19.0 (SPSS Inc., Chicago, IL, USA). Data were summarized as medians \pm SD, with categorical data presented as numbers and percentages. Respondents were divided into two groups based on - age less than or more than 50 years, which were chosen randomly. Categorical variables like; male vs. female, colostomy vs. ileostomy, benign vs. malignant, counseled vs not counselled; were all analyzed using the Pearson's chi square test. Normally distributed continuous variables were analyzed using the independent sample $t$ test. $P$ value $<0.05$ was considered statistically significant.

\section{RESULTS}

\section{A. Stoma Related Surgical Complications:}

Out of 60 patients in our study only 10 patients had preoperative counselling. 50 patients underwent surgery without any preoperative counselling. There are many surgical complications which are related to stoma. In our study we have taken the four most common complications. These are as follows-

1. Skin irritation.

2. Stoma retraction.

3. Stomal prolapse.

4. Parastomal hernia.

The stoma related surgical complications are mainly skin irritation, stoma retraction, stomal prolapsed and parastomal hernia. Out of 60 patients in our study 45 patients have skin irritation around the stoma. Skin involvement ranged from erythema to skin ulcer. Skin erythema around the stoma is more common in case of colostomy, whereas skin ulceration is more common in case of ileostomy. Stomal retraction was found in 6 patients. Revision surgery was done in 4 cases. Stoma prolapse was found in 3 patients and parastomal hernia occurred in 2 patients (Figure 3). Comparisons of complications between 2 age groups were not statistically different (Table 2). Ileostomy patients had higher skin irritation, p value 0.046 (Table 3). Skin irritation was seen in $85.3 \%$ of patients with benign disease against $61.5 \%$ of patients with malignant cause as primary disease, $\mathrm{p}$ value 0.035 (Table 4). Most importantly the effects of preoperative counselling in patients undergoing intestinal stoma have significantly low skin irritation problem $p$ value 0.005 (Table 5).

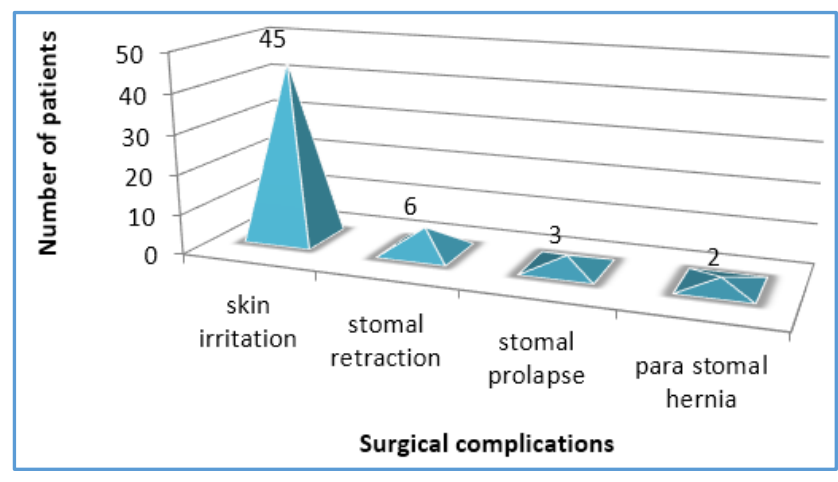

Figure 3. Total Number of Patients Suffering from Surgical Complications

\begin{tabular}{|c|c|c|c|c|c|c|}
\hline \multirow{2}{*}{\multicolumn{2}{|c|}{ Surgical Complications }} & \multicolumn{4}{|c|}{ Age (in years) } & \multirow{3}{*}{\begin{tabular}{|c}
$\begin{array}{c}\mathbf{P} \\
\text { value }\end{array}$ \\
0.058
\end{tabular}} \\
\hline & & \multicolumn{2}{|c|}{$\begin{array}{c}<50 \text { Years } \\
(\mathrm{N}=20)\end{array}$} & \multicolumn{2}{|c|}{$\begin{array}{l}>50 \text { Years } \\
(\mathrm{N}=40)\end{array}$} & \\
\hline \multirow{2}{*}{ Skin Irritation } & No & 2 & $10.0 \%$ & 13 & $32.5 \%$ & \\
\hline & Yes & 18 & $90.0 \%$ & 27 & $67.5 \%$ & \\
\hline \multirow{2}{*}{ Stoma Retraction } & No & 18 & $90.0 \%$ & 36 & $90.0 \%$ & \multirow{2}{*}{1.000} \\
\hline & Yes & 2 & $10.0 \%$ & 4 & $10.0 \%$ & \\
\hline \multirow{2}{*}{ Stoma Prolapse } & No & 19 & $95.0 \%$ & 38 & $95.0 \%$ & \multirow{2}{*}{1.000} \\
\hline & Yes & 1 & $5.0 \%$ & 2 & $5.0 \%$ & \\
\hline \multirow{2}{*}{ Parastomal Hernia } & No & 19 & $95.0 \%$ & 39 & $97.5 \%$ & \multirow{2}{*}{0.611} \\
\hline & Yes & 1 & $5.0 \%$ & 1 & $2.5 \%$ & \\
\hline \multicolumn{7}{|c|}{$\begin{array}{c}\text { Table 2. Comparison of Surgical Complications } \\
\text { between } 2 \text { Age Groups }\end{array}$} \\
\hline
\end{tabular}

\begin{tabular}{|c|c|c|c|c|c|c|}
\hline \multirow{2}{*}{ Surgical Complications } & \multicolumn{3}{|c|}{$\begin{array}{c}\text { Type of ostomy } \\
\text { Colostomy } \\
\text { (N= 23) }\end{array}$} & $\begin{array}{c}\text { Ileostomy } \\
\text { (N=37) }\end{array}$ & \\
\cline { 3 - 6 } & & value \\
\hline \multirow{2}{*}{ Skin Irritation } & No & 9 & $39.1 \%$ & 6 & $16.2 \%$ & \multirow{2}{*}{0.046} \\
\cline { 2 - 6 } & Yes & 14 & $60.9 \%$ & 31 & $83.8 \%$ & \\
\hline \multirow{2}{*}{ Stoma Retraction } & No & 21 & $91.3 \%$ & 33 & $89.2 \%$ & \multirow{2}{*}{0.791} \\
\cline { 2 - 6 } & Yes & 2 & $8.7 \%$ & 4 & $10.8 \%$ & \\
\hline \multirow{2}{*}{ Stoma Prolapse } & No & 22 & $95.7 \%$ & 35 & $94.6 \%$ & \multirow{2}{*}{0.855} \\
\cline { 2 - 6 } & Yes & 1 & $4.3 \%$ & 2 & $5.4 \%$ & \\
\hline \multirow{2}{*}{ Parastomal Hernia } & No & 23 & $100.0 \%$ & 35 & $94.6 \%$ & \multirow{2}{*}{0.257} \\
\cline { 2 - 5 } & Yes & 0 & $.0 \%$ & 2 & $5.4 \%$ & \\
\hline \multirow{7}{*}{ Table 3. Comparison of Surgical Complications between 2 } \\
Types of Ostomies \\
\hline
\end{tabular}

\begin{tabular}{|c|c|c|c|c|c|c|}
\hline \multirow{2}{*}{\multicolumn{2}{|c|}{ Surgical Complications }} & \multicolumn{4}{|c|}{ Primary Cause for Stoma } & \multirow{4}{*}{\begin{tabular}{|c}
$\mathbf{P}$ \\
value \\
0.035
\end{tabular}} \\
\hline & & \multicolumn{2}{|c|}{$\begin{array}{c}\text { Benign } \\
\text { Disease } \\
(n=34)\end{array}$} & \multicolumn{2}{|c|}{$\begin{array}{c}\text { Malignant } \\
\text { Disease } \\
(n=26)\end{array}$} & \\
\hline \multirow{2}{*}{ Skin Irritation } & No & 5 & $14.7 \%$ & 10 & $38.5 \%$ & \\
\hline & Yes & 29 & $85.3 \%$ & 16 & $61.5 \%$ & \\
\hline \multirow{2}{*}{ Stoma Retraction } & No & 30 & $88.2 \%$ & 24 & $92.3 \%$ & \multirow{2}{*}{0.602} \\
\hline & Yes & 4 & $11.8 \%$ & 2 & $7.7 \%$ & \\
\hline \multirow{2}{*}{ Stoma Prolapse } & No & 32 & $94.1 \%$ & 25 & $96.2 \%$ & \multirow{2}{*}{0.720} \\
\hline & yes & 2 & $5.9 \%$ & 1 & $3.8 \%$ & \\
\hline $\begin{array}{l}\text { Parastomal } \\
\text { Hernia }\end{array}$ & no & 32 & $94.1 \%$ & 26 & $100.0 \%$ & \multirow[t]{2}{*}{0.208} \\
\hline yes & $5.9 \%$ & 0 & \multicolumn{2}{|c|}{$.0 \%$} & & \\
\hline \multicolumn{7}{|c|}{$\begin{array}{c}\text { Table 4. Comparison of Surgical Complications based on } \\
\text { Primary Cause of Disease }\end{array}$} \\
\hline
\end{tabular}




\begin{tabular}{|c|c|c|c|c|c|c|}
\hline \multirow{2}{*}{$\begin{array}{c}\text { Surgical } \\
\text { Complications }\end{array}$} & \multicolumn{4}{|c|}{ Counselling } & \multirow{2}{*}{$\begin{array}{c}\text { No } \\
\text { value }\end{array}$} \\
\cline { 2 - 7 } & No & 9 & $18.0 \%$ & 6 & $60.0 \%$ & \multirow{2}{*}{0.005} \\
\hline \multirow{2}{*}{ Skin Irritation } & Yes & 41 & $82.0 \%$ & 4 & $40.0 \%$ & \\
\cline { 2 - 7 } & No & 44 & $88.0 \%$ & 10 & $100.0 \%$ & \multirow{2}{*}{0.248} \\
\cline { 2 - 6 } Stoma Retraction & Yes & 6 & $12.0 \%$ & 0 & $.0 \%$ & \\
\hline \multirow{2}{*}{ Stoma Prolapse } & No & 47 & $94.0 \%$ & 10 & $100.0 \%$ & \multirow{2}{*}{0.427} \\
\cline { 2 - 6 } & Yes & 3 & $6.0 \%$ & 0 & $.0 \%$ & \\
\hline Parastomal Hernia & No & 48 & $96.0 \%$ & 10 & $100.0 \%$ & \multirow{2}{*}{0.520} \\
\cline { 2 - 6 } & Yes & 2 & $4.0 \%$ & 0 & $.0 \%$ & \\
\hline $\begin{array}{c}\text { Table 5. Comparison of Surgical Complications based on } \\
\text { Primary Cause of Disease }\end{array}$ \\
\hline
\end{tabular}

\section{B. Quality of Life: Subscales and Scores Assessments}

The physical wellbeing subscales included 10 items from the original questionnaire, excluding "leaking from the pouch (or around the appliance)". The median physical wellbeing raw score of all patients combing score of 10 items was 72, range 45 to 86. (Table 6) The physical subscale was reverse coded means patients less than 50 years of age, with benign disease, with Ileostomy and with no prior counselling had worse scores than their corresponding variables. (Table 7) There was no difference on the grounds of gender comparison.

\begin{tabular}{|c|c|c|c|c|c|}
\hline $\begin{array}{c}\text { Scores of } \\
\text { Different } \\
\text { Subscales }\end{array}$ & Median & Mini. & Maxi. & $\begin{array}{c}\text { Mean } \pm \\
\text { S.E. }\end{array}$ & S.D. \\
\hline $\begin{array}{c}\text { Physical } \\
\text { Wellbeing Raw } \\
\text { Score }\end{array}$ & 72 & 45.00 & 86.00 & $\begin{array}{c}69.32 \pm \\
1.31\end{array}$ & 10.13 \\
\hline $\begin{array}{c}\text { Physical } \\
\text { Wellbeing Score }\end{array}$ & 7.2 & 4.50 & 8.60 & $\begin{array}{c}6.93 \pm \\
0.13\end{array}$ & 1.013 \\
\hline $\begin{array}{c}\text { Psychological } \\
\text { Wellbeing Raw } \\
\text { Score }\end{array}$ & 65 & 46.00 & 80.00 & $\begin{array}{c}64.52 \pm \\
0.86\end{array}$ & 6.67 \\
\hline $\begin{array}{c}\text { Psychological } \\
\text { Wellbeing Score }\end{array}$ & 6.5 & 4.60 & 8.00 & $\begin{array}{c}6.45 \pm \\
0.09\end{array}$ & 0.67 \\
\hline $\begin{array}{c}\text { Social } \\
\text { Wellbeing Raw } \\
\text { Score }\end{array}$ & 64 & 44.00 & 72.00 & $\begin{array}{c}63.37 \pm \\
0.76\end{array}$ & 5.86 \\
\hline $\begin{array}{c}\text { Social Wellbeing } \\
\text { Score }\end{array}$ & 8 & 5.50 & 9.00 & $\begin{array}{c}7.92 \pm \\
0.09\end{array}$ & 0.73 \\
\hline $\begin{array}{c}\text { Table 6. Descriptive Statistics for Different Subscales of the } \\
\text { Questionnaire for All Patients }\end{array}$ \\
\hline
\end{tabular}

The psychological wellbeing subscale raw score was summation of 10 items, excluding items "are you fearful that your disease will come back?" and "how is your ability to remember things?" The median raw score for all patients was 65 , range 46 to 80 , with score of $6.45 \pm 0.08$. (Table 6 ) The psychological score was higher in non-counseling arm $6.61 \pm$ 0.55 versus $5.68 \pm 0.69$ in counseled arm, p value $<0.001$. Because this subscale score had items 6 out 10 items reverse coded it was evident that pre-operative counseling was beneficial for patients (Table 7).

\begin{tabular}{|c|c|c|c|c|}
\hline \multicolumn{2}{|c|}{$\begin{array}{c}\text { Comparative } \\
\text { Groups }\end{array}$} & \begin{tabular}{|c|} 
Physical \\
Wellbeing \\
Score \\
\end{tabular} & \begin{tabular}{|c|} 
Psychological \\
Wellbeing \\
Score
\end{tabular} & $\begin{array}{c}\text { Social } \\
\text { Wellbeing } \\
\text { Score }\end{array}$ \\
\hline \multirow{3}{*}{ Age } & $\begin{array}{c}<50 \text { years } \\
(\mathrm{N}=20)\end{array}$ & $\begin{array}{l}7.60 \pm \\
0.55\end{array}$ & $\begin{array}{c}6.55 \pm \\
0.58\end{array}$ & $\begin{array}{c}8.19 \pm \\
0.57\end{array}$ \\
\hline & $\begin{array}{c}>50 \text { years } \\
(\mathrm{N}=40)\end{array}$ & $\begin{array}{c}6.59 \pm \\
1.03\end{array}$ & $\begin{array}{c}6.40 \pm \\
0.71\end{array}$ & $\begin{array}{c}7.79 \pm \\
0.77\end{array}$ \\
\hline & $P$ value & $<0.001^{\$}$ & 0.401 & $0.045^{\$}$ \\
\hline \multirow{3}{*}{ Gender } & $\begin{array}{c}\text { Male } \\
(\mathrm{N}=36)\end{array}$ & $\begin{array}{c}6.74 \pm \\
0.92\end{array}$ & $\begin{array}{c}6.58 \pm \\
0.65\end{array}$ & $\begin{array}{l}7.99 \pm \\
0.77\end{array}$ \\
\hline & $\begin{array}{l}\text { Female } \\
(\mathrm{N}=24)\end{array}$ & $\begin{array}{l}7.21 \pm \\
1.09\end{array}$ & $\begin{array}{c}6.25 \pm \\
0.66\end{array}$ & $\begin{array}{c}7.82 \pm \\
0.67\end{array}$ \\
\hline & P value & 0.079 & 0.600 & 0.403 \\
\hline \multirow{3}{*}{$\begin{array}{l}\text { Primary } \\
\text { Disease }\end{array}$} & $\begin{array}{l}\text { Benign } \\
(\mathrm{N}=34)\end{array}$ & $\begin{array}{c}7.53 \pm \\
0.48 \\
\end{array}$ & $\begin{array}{c}6.51 \pm \\
0.56\end{array}$ & $\begin{array}{c}8.15 \pm \\
0.52 \\
\end{array}$ \\
\hline & $\begin{array}{l}\text { Malignant } \\
(\mathrm{N}=26)\end{array}$ & $\begin{array}{c}6.15 \pm \\
0.99 \\
\end{array}$ & $\begin{array}{l}6.37 \pm \\
0.79 \\
\end{array}$ & $\begin{array}{l}7.62 \pm \\
0.86 \\
\end{array}$ \\
\hline & P value & $<0.001 \$$ & 0.429 & $0.005^{\$}$ \\
\hline \multirow{3}{*}{$\begin{array}{l}\text { Type of } \\
\text { Stoma }\end{array}$} & $\begin{array}{c}\text { Ileostomy } \\
(\mathrm{N}=37)\end{array}$ & $\begin{array}{c}7.51 \pm \\
0.48 \\
\end{array}$ & $\begin{array}{c}6.53 \pm \\
0.54 \\
\end{array}$ & $\begin{array}{c}8.15 \pm \\
0.51 \\
\end{array}$ \\
\hline & $\begin{array}{c}\text { Colostomy } \\
(\mathrm{N}=23)\end{array}$ & $\begin{array}{c}6.00 \pm \\
0.96\end{array}$ & $\begin{array}{c}6.32 \pm \\
0.82 \\
\end{array}$ & $\begin{array}{c}7.54 \pm \\
0.87\end{array}$ \\
\hline & P value & $<0.001^{\$}$ & 0.222 & $0.001^{\$}$ \\
\hline \multirow{3}{*}{ Counseling } & Yes $(N=10)$ & $\begin{array}{c}5.21 \pm \\
0.41\end{array}$ & $\begin{array}{c}5.68 \pm \\
0.69\end{array}$ & $\begin{array}{c}7.08 \pm \\
1.02\end{array}$ \\
\hline & No $(\mathrm{N}=50)$ & $\begin{array}{c}7.28 \pm \\
0.69\end{array}$ & $\begin{array}{c}6.61 \pm \\
0.55\end{array}$ & $\begin{array}{c}8.09 \pm \\
0.53\end{array}$ \\
\hline & P value & $<0.001^{\$}$ & $<0.001^{\$}$ & $<0.001^{\$}$ \\
\hline
\end{tabular}

$\$ p$ value $<0.05$ statistically significant. Benign causes for primary disease included strangulated hernia, band adhesion, ileal perforation, volvulus, none of which had carcinoma as precipitating cause.

Table 7. Descriptive Statistics for Different Subscales of the Questionnaire for Comparison between Different Groups

The raw score for social wellbeing subscale was calculated from 8 items out of 12 original items. "Do you have enough privacy when traveling for conducting your ostomy care?", "do you have enough privacy at home for doing your ostomy care?", "has your ostomy interfered with your recreational/sports activities?" and "how much isolation is caused by your ostomy?' items have excluded in these calculations. Median raw score for social well-being is 64 range 44 to 72 . With 6 out 8 items considered for analysis being reverse coded, patients less than 50 years of age, with benign disease, with Ileostomy and with no counselling had worse social well-being scores when compared with their corresponding variables (Table 7). The spiritual wellbeing portion was omitted as majority of the items were not marked by the more than $70 \%$ of patients.

The grand QOL score was calculated by summation of items with scores, i.e. 28 items to yield a median score of 7.20, with mean of 7.04 \pm 0.63 . (Table 8) Excepting gender, all other groups were showing statistically significant comparisons. (Table 9)

\begin{tabular}{|c|c|c|}
\hline \multirow{3}{*}{ Grand QOL Raw Score } & Mean \pm S.D. & $197.2 \pm 17.70$ \\
\cline { 2 - 3 } & Median & 201.5 \\
\cline { 2 - 3 } & Minimum & 143.0 \\
\cline { 2 - 3 } Grand QOL Score & Maximum & 226.0 \\
\hline & Mean \pm S.D. & $7.04 \pm 0.63$ \\
\cline { 2 - 3 } & Median & 7.20 \\
\cline { 2 - 3 } & Minimum & 5.11 \\
\cline { 2 - 3 } Table 8. Descriptive Statistics for Grand QoL Scores \\
for All Patients \\
\hline
\end{tabular}




\begin{tabular}{|c|c|c|c|}
\hline \multicolumn{2}{|c|}{ Different Groups } & Mean \pm S.D. & P value \\
\hline \multirow{2}{*}{ Age } & $<50$ years $(\mathrm{N}=20)$ & $7.39 \pm 0.28$ & \multirow{2}{*}{0.002} \\
\hline & $>50$ years $(\mathrm{N}=40)$ & $6.87 \pm 0.69$ & \\
\hline \multirow{2}{*}{ Gender } & Male $(\mathrm{N}=36)$ & $7.04 \pm 0.64$ & \multirow{2}{*}{0.986} \\
\hline & Female $(\mathrm{N}=24)$ & $7.04 \pm 0.63$ & \\
\hline \multirow{2}{*}{$\begin{array}{c}\text { Primary } \\
\text { disease }\end{array}$} & Benign $(\mathrm{N}=34)$ & $7.34 \pm 0.27$ & \multirow{2}{*}{$<0.001$} \\
\hline & Malignant $(\mathrm{N}=26)$ & $6.65 \pm 0.75$ & \\
\hline \multirow{2}{*}{ Type of stoma } & yy $(N=37)$ & $7.35 \pm 0.27$ & \multirow{2}{*}{$<0.001$} \\
\hline & Colostomy $(\mathrm{N}=23)$ & $6.56 \pm 0.74$ & \\
\hline \multirow{2}{*}{ Counseling } & Yes $(\mathrm{N}=10)$ & $5.91 \pm 0.56$ & \multirow{2}{*}{$<0.001$} \\
\hline & No $(N=50)$ & $7.27 \pm 0.33$ & \\
\hline & & 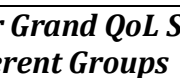 & \\
\hline
\end{tabular}

\section{DISCUSSION}

Findings of the current study suggest that living with a stoma affects QOL. The mean age of the patients included in study was $55.17 \pm 17.23$ years. In total $36(60 \%)$ patients were males against $24(40 \%)$ female patients who participated in the study. Out of 22 patients with colostomy 14 patients had permanent colostomy and 8 patients had temporary colostomy. Permanent colostomy was done on patients with carcinoma of colon and rectum. In 26 patients, stoma was done for carcinoma of large gut. Strangulated hernia was the cause of stoma formation in 18 patients. Band adhesion and gut necrosis was the cause in 10 patients. In 4 patients, ileal perforation was the cause of stoma. Crohn's disease was the cause of stoma in 2 patients. The mean duration for patients having the stoma was $5.26 \pm 2.86$ months.

When assessing the marital status prior to the surgery for stoma, out of 60 patients in our study the marital status was, 34 patients were married, 16 patients were single, 8 patients were widowed, and 2 patients were divorced. However, after the surgery for stoma 2 patients were divorced and 2 patients were widowed.

According to the results, only 4 patients out of initial 24 patients reported that they have resumed sexual activity after stoma surgery. $[2,3]$ The findings of the current study are consistent with other studies.[4,5] This was in sharp contrast to a study conducted by Gemmill et al.,[6] where $70 \%$ of patients had sexual activity before stoma surgery, while only $55 \%$ of patients resumed their sexual activity after surgery. This may be due to lack of proper training on sexuality issues to stoma patients. The same results were replicated in an Indian study with results with $57 \%$ patients reporting Impact on sexual desires, sexual behaviour and sexual health due to stoma bag. Feeling of embarrassment, anxiety, refraining from sexual act and maladjustment towards sexual life was seen in $25 \%$ patients. In $7 \%$ patients the spouse rejected the partner because of the stoma bag.[7] Therefore, it may be useful to refer stoma patients for counselling and training about sexual health ${ }^{[8,9]}$ All the patients were depressed and anxious after having a stoma. The results of which are consistent with other studies.[10-13] Depression was due to the disease process and disfigurement of body.[14] Four patients had attempted suicide with one succumbing to death. Most of the patients with stoma felt fatigued throughout the day. The fatigue is more common in cases of Ileostomy.

The stoma related surgical complications were mainly skin irritation, stoma retraction, stomal prolapsed and parastomal hernia. The skin irritation and involvement ranged from erythema to skin ulcer. Skin erythema around the stoma was more common in case of colostomy, whereas skin ulceration is more common in case of ileostomy. Stomal retraction was found in 6 patients. Revision surgery was done in 4 cases. Stoma prolapse was found in 3 patients and parastomal hernia occurred in 2 patients. Skin irritation was seen in $85.3 \%$ of patients with benign disease against $61.5 \%$ of patients with malignant cause as primary disease, $p$ value 0.035. Patients with ileostomy had much serious problems than colostomies.

The description by Dabrian in a latest article showed The purpose of stoma is to treat and reduce patients' pain and discomfort, but in many cases stoma leads to intensified distress and suffering for patients, and causes severe stress as a result of skin irritation (76\%), pouch leakage (62\%), offensive odour (59\%), reduction in pleasurable activities (54\%), and depression/anxiety (53\%). Our study shows preoperative counselling decreases the stoma related surgical complications. Worldwide the impact of stoma is more adverse in veterans than young population. Pittman showed skin problem, leakage and complications of stoma are predicted by increasing age, employment, income, preoperative care and post-operative stoma management.[14] Probably careful preoperative planning, counselling may be helpful in devising methods to decrease complications.[15]

The mean physical wellbeing score of all patients combining score of 10 items was $6.93 \pm 1.01$. The physical subscale was reverse coded means patients less than 50 years of age, with benign disease, with Ileostomy and with no prior counselling had worse scores than their corresponding variables. There was no difference on the grounds of gender comparison. The median psychological raw score for all patients was 65 , range 46 to 80 , with score of $6.45 \pm 0.08$. The psychological score was higher in non-counselling arm $6.61 \pm$ 0.55 versus $5.68 \pm 0.69$ in counselled arm, $p$ value $<0.001$. Because this subscale score had items 6 out 10 items reverse coded it was evident that pre-operative counselling was beneficial for patients. The patients less than 50 years of age, with benign disease, with Ileostomy and with no counselling had worse social well-being scores when compared with their corresponding variables. The mean social well-being score was $7.92 \pm 0.73$. The similar results to this study were obtained as reported by Scarpa.[16]

The grand QOL score was calculated by summation of items with scores, i.e. 28 items to yield a median score of 7.20 , with mean of $7.04 \pm 0.63$. Excepting gender, all other groups were showing statistically significant comparisons. The results are little different from other studies. In one study done by Krouse R in assessment of QOL in 599 cancer and non-cancer patients with colostomies confirmed the negative impact of colostomy on QOL. Interestingly this study showed that patients with cancer had better quality of life with common QOL problems being sexual, gas, constipation, travel difficulties and dissatisfaction with appearance. The study ended by discussing the role of pre-operative counselling to improve the QOL.[17]

This study design had some drawbacks. One important component of QOL questionnaire i.e spiritual wellbeing along specific items of other subscales was omitted. Secondly being a cross-sectional study, change in QOL over time was not noted. This grossly undermines the necessity of continuous monitoring and counselling of patient and care of stoma. Thirdly after closure of stoma wound the change in QOL was not accounted for in individuals with temporary stoma. 
Fourthly socioeconomic status was not considered as important co-factor in the study. Lastly, in spite of this study being conducted in tertiary care hospital, study population was small with time constraints.

\section{CONCLUSION}

Living with stoma influences the overall aspect of QOL. The various aspects of a patient's life affected are thus independent of the affection by the disease. Important issues of concern are the low Quality of Life score in ileostomy, severe complication rates particularly in ileostomy, serious jeopardy of sexual health and the financial burden for the patient \& his family. These could be overcome by preoperative counselling. Identification of the data in the perspective of scant presence of Indian data will allow caregivers to formulate strategies for better stoma management with formation of the team strategy for the stoma care team.

Pre- and post-operative education for the patients and their families is important so that the stoma patients' QOL can be improved. Training is required to improve sexual activity in stoma patients. Psychological support from family and friends is essential to alleviate concerns about mental well-being. Colostomy groups should be created so that patients with stoma can understand their problems better and can support each other. Larger multi-institutional longitudinal study is required for assessment and ways to improve QOL in patients with stoma.

\section{REFERENCES}

[1] United Ostomy Association publication, which was distributed to attendees at the WOCN conference in June 2011. Ostomy Surgeries and The Ostomy Population 2011: p. 1-2.

[2] Anaraki F, Vafaie M, Behboo R, et al. Quality of life outcomes in patients living with stoma. Indian J Palliat Care 2012;18(3):176-80.

[3] Bossema ER, Seuntiëns MW, Marijnen CA, et al. The relation between illness cognitions and quality of life in people with and without a stoma following rectal cancer treatment. Psychooncology 2011;20(4):428-34.

[4] Marquis P, Marrel A, Jambon B. Quality of life in patients with stomas: The Montreux Study. Ostomy Wound Manage 2003;49(2):48-55.

[5] Carlsson E, Berndtsson I, Hallen AM, et al. Concerns and quality of life before surgery and during the recovery period in patients with rectal cancer and an ostomy. J Wound Ostomy Continence Nurs 2010;37(6):654-61.
[6] Grant M, Ferrell B, Dean G, et al. Revision and psychometric testing of the City of Hope Quality of Life-Ostomy Questionnaire. Qual Life Res 2004;13(8):1445-57.

[7] Shaffy, Kaur S, Das K, et al. Physical, nutritional and sexual problems experienced by the patients with colostomy/ileostomy: a qualitative study. Nursing and Midwifery Research Journal 2012;8(3):210-21.

[8] Dabirian A, Yaghmaei F, Rassouli M, et al. Quality of life in stoma patients: a qualitative study. Patient Prefer Adherence 2011;5:1-5.

[9] Grant M, McMullen CK, Altschuler A, et al. Gender differences in quality of life among long-term colorectal cancer survivors with ostomies. Oncol Nurs Forum 2011;38(5):587-96.

[10] Aronovitch SA, Sharp R, Harduar-Morano L. Quality of life for patients living with ostomies: influence of contact with an ostomy nurse. J Wound Ostomy Continence Nurs 2010;37(6):649-53.

[11] Gemmill R, Sun V, Ferrell B, et al. Going with the flow: quality-of-life outcomes of cancer survivors with urinary diversion. J Wound Ostomy Continence Nurs 2010;37(1):65-72.

[12] Colquhoun P, Kaiser R Jr, Efron J, et al. Is the quality of life better in patients with colostomy than patients with fecal incontience? World J Surg 2006;30(10):1925-8.

[13] Gooszen AW, Geelkerken RH, Hermans J, et al. Quality of life with a temporary stoma: Ileostomy vs. colostomy. Dis Colon Rectum 2000;43(5):650-5.

[14] Makela JT, Niskasaari M. Stoma care problems after stoma surgery in Northern Finland. Scand J Surg 2006;95(1):23-7.

[15] Turnbull GB, Arnold A, Aronson L, et al. The role of industry in improving quality of life for persons with an ostomy: a Canadian consensus. Ostomy Wound Manage 2004;50(9):78-85.

[16] Scarpa M, Barollo M, Polese L, et al. Quality of life in patients with an ileostomy. Minerva Chir 2004;59(1):23-9.

[17] Krouse R, Grant M, Ferrell B, et al. Quality of life outcomes in 599 cancer and non-cancer patients with colostomies. J Surg Res 2007;138(1):79-87. 